\title{
Sampling Efficiency and Performance of Selected Thoracic Aerosol Samplers
}

\author{
Peter Görner, Xavier Simon, Alexis Boivin, Sébastien Bau \\ Institut National de Recherche et de Sécurité (INRS), Rue du Morvan, \\ CS 60027, 54519 Vandouvre les Nancy, France
}

\begin{abstract}
Measurement of worker exposure to a thoracic health related aerosol fraction is necessary in a number of occupational situations. This is the case of workplaces with atmospheres polluted by fibrous particles, such as cotton dust or asbestos, and by particles inducing irritation or bronchoconstriction such as acid mists or flour dust. Three personal and two static thoracic aerosol samplers were tested under laboratory conditions. Sampling efficiency with respect to particle aerodynamic diameter was measured in a horizontal low wind tunnel and in a vertical calm air chamber. Sampling performance was evaluated against conventional thoracic penetration.

Three of the tested samplers performed well, when sampling the thoracic aerosol at nominal flow rate and two others performed well at optimized flow rate. The limit of flow rate optimization was found, when using cyclone samplers.
\end{abstract}

Keywords:

thoracic aerosol; sampling efficiency; sampler performance; exposure measurement 


\section{INTRODUCTION}

Workplace exposure to atmospheric aerosols is usually measured in one of three conventional health-related aerosol fractions (CEN, 1993; ISO, 1995; ACGIH, 1995). Measurement of the inhalable, thoracic or respirable fraction is necessary depending on the definition of Threshold Limit Value (TLV) for different particulate substances. While inhalable and respirable aerosol measurement is common practice, the thoracic fraction is only rarely measured. The thoracic aerosol fraction was first measured in the US cotton industry to assess the risk of byssinosis (Corn, 1987) by using a vertical elutriator operated at $7.4 \mathrm{~L} \cdot \mathrm{min}^{-1}$ (Lynch, 1970). The Workshop on Fiber Toxicology Research Need, held in 1989, recommended "the use of size selective inlets such as thoracic particulate matter for fibrous aerosol sampling" (Dement, 1990). This recommendation continues to be applied nowadays especially when sampling of asbestos.

The aerosol thoracic fraction is also relevant in the case of substances having a local effect on the conductive respiratory airways, more specifically irritation or bronchoconstriction (Fabriès et al., 1998), for example acid mists and flour dust (Laurière et al., 2008). In the wake of a number of epidemiological studies (Soskolne et al., 1984, 2011), it was suggested that the conventional thoracic fraction would best indicate exposure of employees to sulfuric acid (Lippmann et al., 1987). In 2009, EU Directive 2009/161/EU defined the indicative Occupational Exposure Limit Value (OELV) for sulfuric acid mist as $0.05 \mathrm{mg} . \mathrm{m}^{-3}$ in the thoracic fraction.

A suitable thoracic aerosol sampler with a sampling efficiency that meets standardized sampling criteria (CEN, 2014) is necessary in the workplace exposure measurement. In the last 20 years, a number of thoracic aerosol samplers have been developed and their efficiencies have been tested using isometric or fibrous aerosols (Kauffer et al., 1996; Fabriès et al., 1998; Maynard, 1999, 2002; Jones et al., 2005), while other thoracic aerosol samplers have been recently developed. The aim of this study was to measure in the laboratory sampling efficiency of these samplers and to compare it with conventional thoracic penetration criteria. Bias maps were plotted for a series of particle size distributions likely to occur in the workplace (Görner and Fabriès, 1996) to evaluate their performance.

\section{MATERIALS AND METHODS}

\section{Selected thoracic aerosol samplers}

Table 1 lists and details the thoracic aerosol samplers studied along with their respective flow rates. Sampler choice was guided by availability, flow rate, expected efficiency and experience in their use and handling.

Although worker exposure is measured using personal samplers, use of static devices may be preferable in specific cases. Static sampling generally allows implementation of higher sampling flow rates and collection of more material for more accurate analysis. Static sampling is also recommended for pollution mapping studies on industrial sites. 
Table 1. Thoracic aerosol samplers under study

\begin{tabular}{|c|c|c|c|c|c|}
\hline Sampler & CATHIA-T & $\begin{array}{c}\text { Cyclone } \\
\text { GK } 2.69 \\
\text { SS-T }\end{array}$ & $\begin{array}{l}\text { Cyclone } \\
\text { GK 4.162 } \\
\text { Rascal-T }\end{array}$ & $\begin{array}{c}\text { Cyclone IFA } \\
\text { FSP10 }\end{array}$ & $\begin{array}{c}\text { Parallel } \\
\text { Impactor } \\
\text { PPI-T }\end{array}$ \\
\hline Provider & $\begin{array}{l}\text { Tecora } \\
(\mathrm{F})\end{array}$ & $\begin{array}{l}\text { BGI } \\
\text { (US) }\end{array}$ & $\begin{array}{l}\text { BGI } \\
\text { (US) }\end{array}$ & $\begin{array}{l}\text { IFA } \\
(\mathrm{G})\end{array}$ & $\begin{array}{l}\text { SKC } \\
\text { (US) }\end{array}$ \\
\hline $\begin{array}{l}\text { Nominal } \\
\text { flow rate }\end{array}$ & $\begin{array}{c}\mathbf{7 . 0} \\
\text { L.min }^{-1} \\
\end{array}$ & $\begin{array}{c}\mathbf{1 . 6} \\
\text { L.min }\end{array}$ & $\begin{array}{c}\mathbf{4 . 5} \\
\text { L.min } \\
\end{array}$ & $\begin{array}{c}5.34 \\
\text { L.min } \\
\end{array}$ & $\begin{array}{c}\mathbf{2 . 0} \\
\text { L.min }\end{array}$ \\
\hline $\begin{array}{l}\text { Optimized } \\
\text { flow rate }\end{array}$ & $\begin{array}{c}\mathbf{7 . 0} \\
\text { L.min }^{-1}\end{array}$ & $\begin{array}{c}\mathbf{1 . 6} \\
\text { L.min }\end{array}$ & $\begin{array}{c}\mathbf{3 . 0} \\
\text { L.min }^{-1}\end{array}$ & $\begin{array}{c}\mathbf{3 . 5} \\
\text { L.min } \\
\end{array}$ & $\begin{array}{c}\mathbf{2 . 0} \\
\text { L.min }\end{array}$ \\
\hline $\begin{array}{l}\text { Sampling } \\
\text { strategy }\end{array}$ & Static & Personal & Personal & $\begin{array}{l}\text { Static or } \\
\text { personal }\end{array}$ & Personal \\
\hline Photograph & & & & & \\
\hline
\end{tabular}

In this study, the CATHIA-T is considered as the reference sampler what is based on its known sampling efficiency (Fabriès et al., 1998; Maynard, 1999, 2002; Jones et al., 2005). This enables the reliability of our experimental methodology to be checked.

\section{Experimental methodology}

Experimental aerosol sampling efficiency as a function of aerodynamic diameter is usually measured in dust chambers or wind tunnels, to which monodisperse or polydisperse aerosol generators are fitted. Airborne particles are sampled by a reference probe and a candidate sampler. For a given particle size $\mathrm{D}_{\mathrm{a}}$, the ratio of concentrations sampled by the candidate $\mathrm{C}_{\mathrm{c}}\left(\mathrm{D}_{\mathrm{ae}}\right)$ to those sampled by reference probe $\mathrm{C}_{\mathrm{r}}\left(\mathrm{D}_{\mathrm{ae}}\right)$ provides the aerosol sampling efficiency $\mathrm{E}\left(\mathrm{D}_{\mathrm{ae}}\right)$. Thus

$$
\mathrm{E}\left(\mathrm{D}_{\mathrm{ae}}\right)=\mathrm{C}_{\mathrm{c}}\left(\mathrm{D}_{\mathrm{ae}}\right) / \mathrm{C}_{\mathrm{r}}\left(\mathrm{D}_{\mathrm{ae}}\right)
$$

The reference probe sampling efficiency is assumed to be $100 \%$ within the range of particle diameters investigated. The experimental efficiency of the candidate sampler is compared with the conventional thoracic efficiency curve (CEN, 1993; ISO, 1995; ACGIH, 1995) defined by the probability of particle penetration beyond the larynx. This probability is 
expressed by mathematical relation provided by Soderholm (1989) and commented by Görner and Fabriès (1996).

The experimental method used in this study has been described in detail and qualified in our earlier publications. We used two experimental set-ups: a horizontal low velocity $(0.15$ m.s ${ }^{-1}$ ) wind tunnel (Fabriès et al., 1980, 1984; Görner et al., 2001) and a vertical dust chamber (Görner et al., 2008, 2010). The horizontal wind tunnel is approximately $10 \mathrm{~m}$ in length. Within this tunnel, the sampler is placed in the test zone corresponding to a $1 \mathrm{~m} \times 1 \mathrm{~m}$ crosssectioned area located around the middle of the tunnel. The flow is stabilized between the aerosol generation and the test area by means of a 6-mm honeycomb mesh completed by a 0.75-mm grid mesh at its outlet. Besides, the calm air tunnel provides a downward supply of aerosol particles to its measuring zone. Only the particle generator and small dilution air streams enter the cylindrical section with $0.4 \mathrm{~m}$ in diameter, making the air flow very close to calm air $\left(0.027 \mathrm{~m} . \mathrm{s}^{-1}\right)$.

In both cases, a solid polydisperse aerosol was produced by a fluidized-bed aerosol generator (Guichard, 1976). This unit was complemented by a corona discharger to ensure the electrical neutrality of the generated particles. The experimental aerosol was composed of

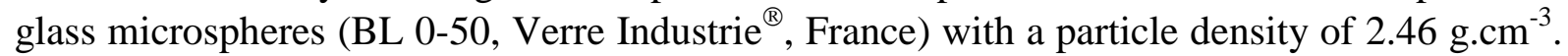
The experimental aerosol size distribution should be within the thoracic penetration interval below about $30 \mu \mathrm{m}$ ). In the horizontal wind tunnel, the log-normal particle size distribution of the generated aerosol was characterized by a mass median aerodynamic diameter MMAD of $10.30 \mu \mathrm{m}$ and a geometric standard deviation GSD of 1.98. The aerosol size distribution in the horizontal wind tunnel was shifted towards smaller particles because of coarse particle sedimentation in the horizontal low air stream. In the vertical dust chamber, MMAD was $15.06 \mu \mathrm{m}$ and GSD was 2.04.

Aerodynamic Particle Sizer (APS 3321, TSI Inc.) was used to measure particle sizeresolved aerosol concentration (Lidén and Kenny, 1991; Fabriès et al., 1998). APS measurements are based on the time-of-flight measurement of accelerated particles, which is directly related to their aerodynamic diameter. The APS aerodynamic diameter range was within the 0.5 to approximately $20 \mu$ interval.

The nominal aerosol flow rate of the APS was 5 L. $\mathrm{min}^{-1}$. When the tested sampler operated at a different flow rate, an in-house isokinetic isoaxial aerosol diluter (Görner et al., 2001) was integrated in two different ways based on whether the sampling flow rate was higher or lower than 5 L. $\mathrm{min}^{-1}$.

Different reference probes were used, depending on the sampler under study. The flow rate of the reference probe was invariably the same as the flow rate of the tested sampler. The connection tube to the aerosol diluter was also the same to ensure identical transmission efficiency in both cases. The reference probes were designed based on the models provided by Hangal and Willeke (1990) and Grinshpun et al (1993) for calculating aspiration efficiency with respect to flow rate, inlet diameter and wind direction. Reference probe efficiency was close to 1 with minimum of 0.98 at $20 \mu \mathrm{m}$ within the measured particle size interval.

Reference and candidate sampling can be performed simultaneously or consecutively. Simultaneous sampling requires perfect spatial homogeneity of the aerosol and two APSs. We therefore opted for consecutive sampling. Reference and candidate sampling was performed on the tunnel axis in the following order: reference - candidate - reference. Aerosol stability in time was continuously checked by an optical particle counter (Grimm 1.108, Grimm Industry $\mathrm{GmbH}$, Germany). The experimental efficiency data were accepted only when the aerosol number concentration varied by no more than $\pm 5 \%$ in each channel during the entire sampling sequence (reference - candidate - reference).

To ensure the reliability of our experimental results, we used both experimental setups - the horizontal low velocity wind tunnel and the vertical dust chamber - to measure the 
sampling efficiency of the reference sampler CATHIA-T. Except CATHIA-T, which inlet is omnidirectional, all other samplers have "oriented" sampling orifices. When comparing the results with various sampler orientations in the horizontal tunnel, slight differences were observed. We therefore used the horizontal low wind speed tunnel which allows orientationaveraged results to be provided for all personal samplers in this study. Furthermore, the wind speed in this tunnel $\left(0.15 \mathrm{~m} . \mathrm{s}^{-1}\right)$ is close to the wind speeds currently encountered in the workplace. Indeed, Baldwin and Maynard (1998) reported that $85 \%$ of workplace wind speeds are lower than $0.3 \mathrm{~m} . \mathrm{s}^{-1}$ and lower than $0.1 \mathrm{~m} \cdot \mathrm{s}^{-1}$ in most cases). Thus, the methodology adopted in this work leads to results as close as possible to the real sampling situation in slightly moving air and with random oriented workers wearing a sampler.

\section{Efficiency data treatment and sampler performance calculation}

Each data point and error bar represents the mean value and one standard deviation for 3 to 10 experimental runs. Experimental efficiency data were modeled by a suitable analytical function using a weighted least-squares method (Fabriès et al., 1998). A decreasing cumulative log-normal law was used to model cyclone efficiency because cyclone separators exhibit naturally similarly shaped efficiency curves. For other samplers, the decreasing cumulative log-normal law was multiplied by the Vincent and Armbruster (1981) inhalability function (noted V.A. in the figures). It is indeed this type of combined law that effectively defines the conventional thoracic and respirable penetrations (Soderholm, 1989).

The decreasing cumulative log-normal law can be written as:

$$
\mathrm{E}\left(\mathrm{D}_{\mathrm{ae}}\right)=[1-\mathrm{F}(\mathrm{x})]
$$

where $\mathrm{F}(\mathrm{x})$ is the cumulative probability function of a standardized normal variable $\mathrm{x}$ :

$$
\mathrm{x}=\ln \left(\mathrm{D}_{\mathrm{ae}} / \mathrm{D}_{50}\right) / \ln (\mathrm{GSD}),
$$

where $\mathrm{D}_{50}$ is the particle diameter, for which the penetration efficiency is $50 \%$. GSD is the Geometric Standard Deviation. $\mathrm{D}_{50}$ and GSD are parameters to be optimized to fit the experimental efficiency data.

The Vincent and Armbruster (1981) inhalable efficiency function is expressed as:

$$
\mathrm{E}\left(\mathrm{D}_{\mathrm{ae}}\right)=\mathrm{P}_{1} \times\left(1+\exp \left(-\mathrm{P}_{2} \times \mathrm{D}_{\mathrm{ae}}\right)\right)
$$

where $P_{1}$ and $P_{2}$ are the parameters to be adjusted (they are 0.5 and 0.06 respectively in the conventional definition of inhalability).

The model enabled us to compare experimental sampling efficiency with the conventional thoracic penetration curve and to compute a bias map of aerosol concentration measurements for a set of simulated aerosol size distributions. The bias calculation method has been described elsewhere (Lidén and Kenny 1992; Görner and Fabriès, 1996; Fabriès et al., 1998; CEN, 2014). The Bias Performance Criterion (BPC) (Görner et al, 2001) was then calculated to provide a simple expression of sampler performance. BPC corresponds to the proportion of simulated aerosols, for which the mass concentration measurement bias is within $\pm 10 \%$. The simulated aerosols comprised a set of log-normal distributions with $1<$ MMAD $<25 \mu \mathrm{m}$ in 1 $\mu \mathrm{m}$ increments and $2<\mathrm{GSD}<3.5$ in 0.25 increments. 


\section{RESULTS AND DISCUSSION}

Validation of methodology by experiments on CATHIA-T

The CATHIA-T (Tecora, France) sampler was designed at INRS and is protected by a French patent (Fabriès et al., 1988). CATHIA-T's high flow rate $\left(7 \mathrm{~L} \cdot \mathrm{min}^{-1}\right)$ imposes a high volume pump, so this sampler can only be used for static sampling (Fabriès et al., 1998; Kauffer et al., 1996). The instrument has been previously investigated (Maynard, 1999, 2002; Jones et al., 2005) and is currently used mainly for asbestos sampling in France.

The CATHIA-T sampler was included in this study in order to check the reliability of the experimental methods used. Fig. 1a illustrates efficiency data measured in calm air vertical tunnel (10 runs) along with the fitted efficiency curve and the conventional thoracic penetration. This figure shows that the experimental data follow closely the thoracic convention.

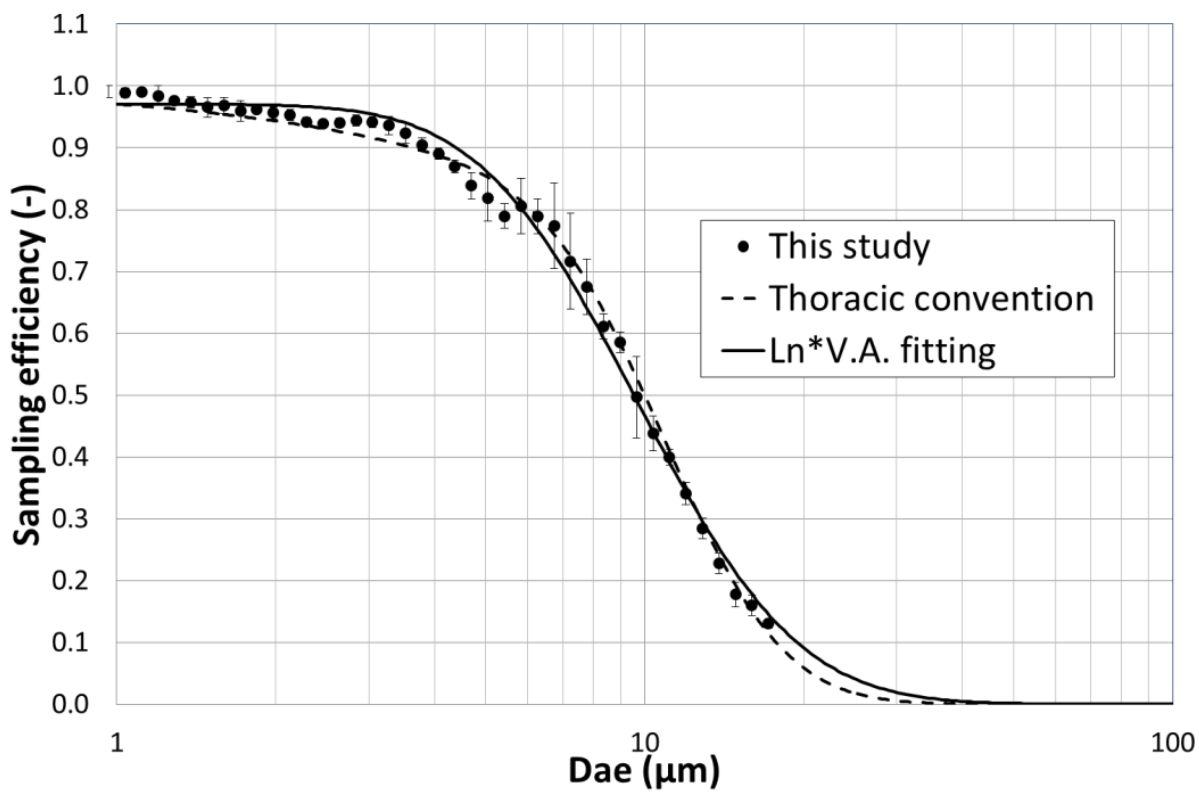

(a)

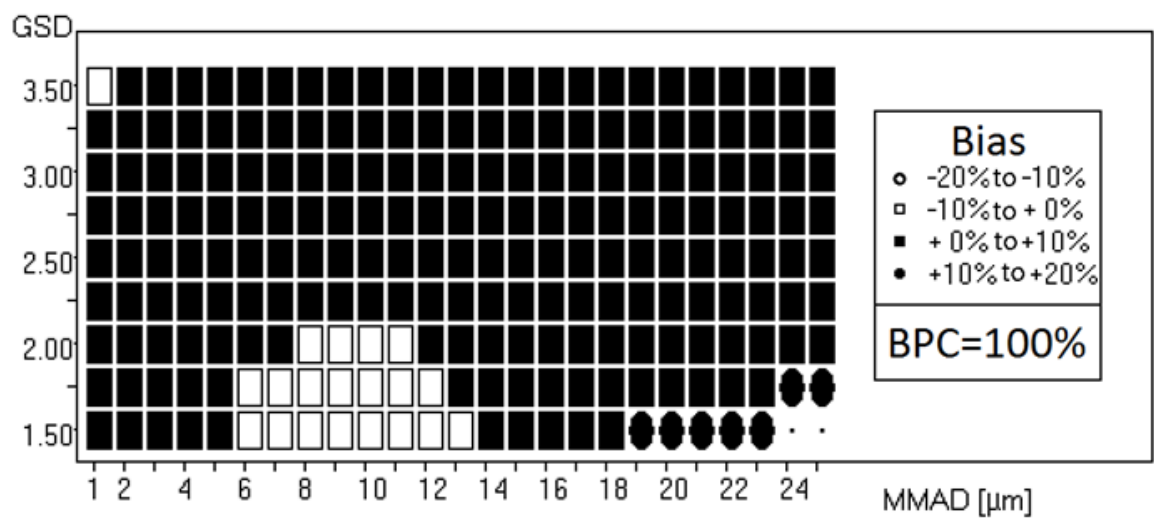

(b)

Fig. 1. Sampling efficiency (a) and bias map (b) for CATHIA-T aerosol sampler at 7 L.min ${ }^{-1}$

The experimental data were fitted by multiplying the decreasing cumulative log-normal law by the Vincent \& Armbruster (1981) inhalability function as explained in previous section. 
The optimized parameters are:

$$
\begin{gathered}
\mathrm{D}_{50}=9.74 \mu \mathrm{m} \\
\mathrm{GSD}=1.73 \\
\mathrm{P}_{1}=0.4853 \\
\mathrm{P}_{2}=0
\end{gathered}
$$

The minimum value of least-squares function $\chi^{2}$ (Fabriès et al., 1998) is reached, when parameter $\mathrm{P}_{2}$ is zero. This means that the best fit corresponds to the log-normal law multiplied by a constant $2 \mathrm{P}_{1}$.

The CATHIA-T sampling performance provided by the bias map (Fig. 1b) mirrors previous results (Fabriès et al., 1998) obtained under different methodological conditions with different experimental set ups, test aerosols (mineral dusts) and data fits. This confirms the equivalence of the experimental methods, especially in the case of sampler with omnidirectional inlet. Indeed, we prefer showing in this paper the result obtained in calm air chamber, not published yet, instead of similar results from horizontal wind tunnel.

Note that all further results concerning personal samplers are issued from the horizontal wind tunnel for the reason given at the end of the section "Experimental methodology". 


\section{Cyclone GK 2.69}

The BGI GK 2.69 cyclone (Mesa Laboratories, USA) was designed by Kenny and Gussman (1997) and is mainly used for respirable aerosol sampling at a flow rate of $4.2 \mathrm{~L} \cdot \mathrm{min}^{-1}$ (Stacey et al., 2014). For thoracic aerosol sampling, the flow rate must be reduced to 1.6 L.min ${ }^{-1}$ (Maynard, 1999).

Experimental sampling efficiency was measured in the horizontal low velocity wind tunnel. The sampler was asymmetrical so it was tested in four orientations: forward, backward, left or right with respect to the air flow. Three runs were performed in each position. The backward orientation is highly improbable in personal sampling and the operator is moving so an average of three orientations (forward, left and right) was considered to represent the sampling efficiency (Fig. 2a). The experimental standard deviation SD is mainly caused by sampler orientation (contribution of $60-80 \%$ to overall SD) rather than by run reproducibility. Experimental efficiency points were modeled by a decreasing cumulative log-normal law, also reported in Fig. 2a.

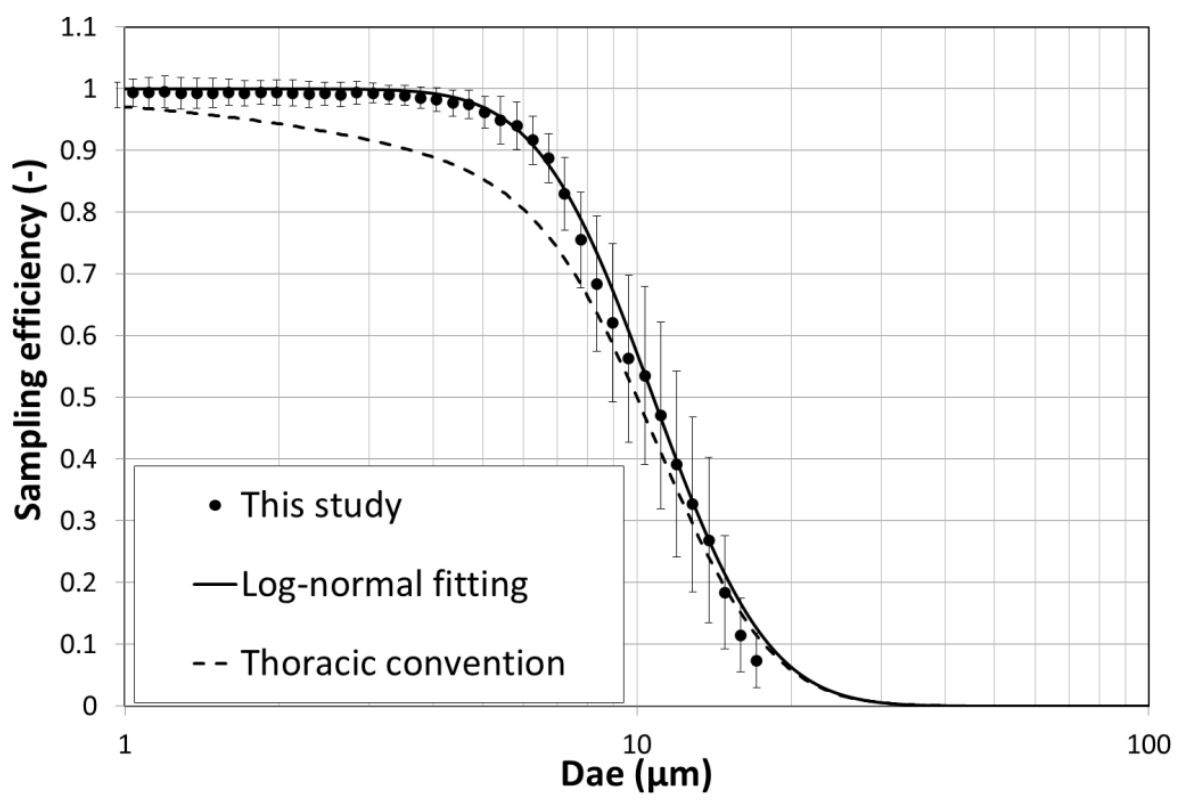

(a)

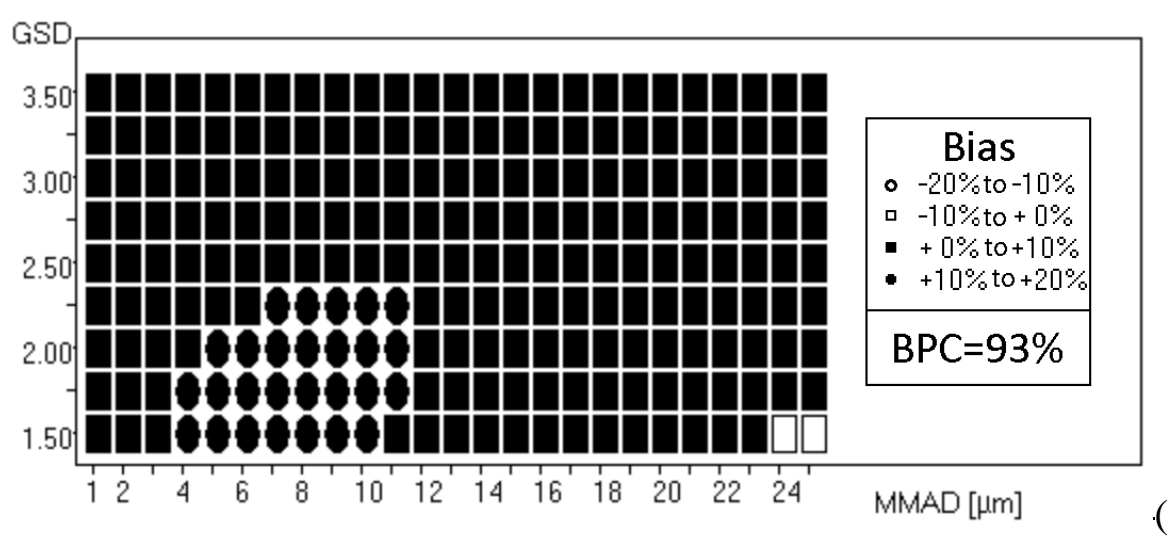

(b)

Fig. 2. Sampling efficiency (a) and bias map (b) of Cyclone GK 2.69 aerosol sampler operated at $1.6 \mathrm{~L} \cdot \mathrm{min}^{-1}$ 
Optimized values of model parameters $\mathrm{D}_{50}$ and GSD are:

$$
\begin{gathered}
\mathrm{D}_{50}=10.49 \mu \mathrm{m} \\
\mathrm{GSD}=1.49
\end{gathered}
$$

The above parameters and those of conventional penetration (CEN, 1993) allow us to simulate numerically thoracic aerosol concentrations for a set of different polydisperse aerosols and this led to the bias map illustrated in Fig. 2b. This bias map shows that the GK 2.69 sampler oversamples slightly (up to 12\%) the aerosol thoracic fraction. The BPC indicates that the bias remain below $10 \%$ for $93 \%$ of the aerosol distributions considered.

The GK 2.69 cyclone was previously studied for the respirable $\left(4.2 \mathrm{~L}^{-\mathrm{min}^{-1}}\right)$ and thoracic (1.6 L.min ${ }^{-1}$ ) fractions (Kenny and Gussman, 1997; Maynard, 1999; Lee et al., 2010). In Fig. 3, these earlier results are compared with this study by means of a ' $\mathrm{D}_{50}$ vs. flow rate' data plot. The ASTEX experimental points reflect the $D_{50}$ values previously obtained in the INRS laboratory for the thoracic flow rate of the GK 2.69 based on two different methods (API and Coulter) applied in an international round robin test (the Aerosol Sampler Testing Exchange) (Kenny, 2000; Lidén, 2000; Görner et al., 2000). Fig. 3 also includes the INRS $D_{50}$ value for the $4.2 \mathrm{~L} \cdot \mathrm{min}^{-1}$ respirable flow rate provided by the present study. All experimental results closely follow the cyclone design model (http://bgi.mesalabs.com/cyclonefractionators/) at higher flow rates $\left(\approx 4 \mathrm{~L} \cdot \mathrm{min}^{-1}\right)$. At lower flow rates $\left(<2 \mathrm{~L} \cdot \mathrm{min}^{-1}\right)$, the " $\mathrm{D}_{50^{-}}$ flow rate" function is very steep and a large $\mathrm{D}_{50}$ shift can be observed with a small flow rate variation. This dictates meticulous flow rate control in real field sampling.

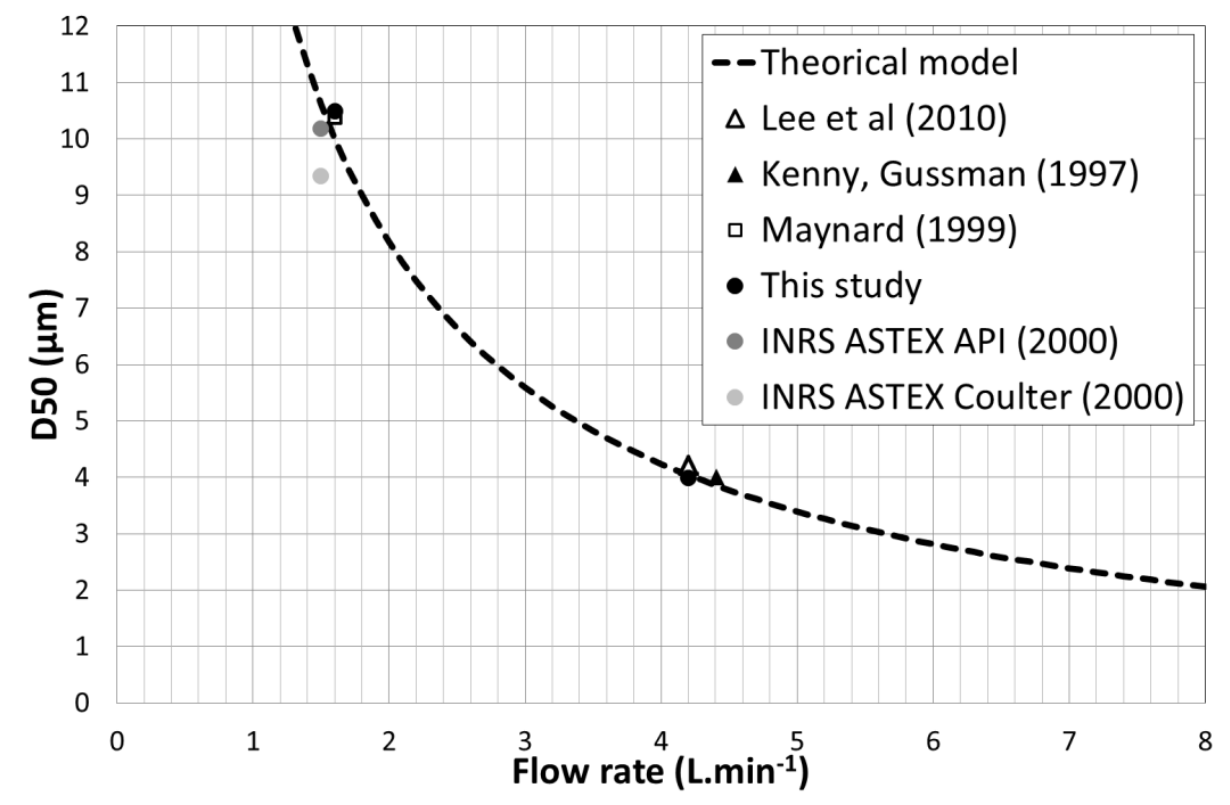

Fig. 3. "D $\mathrm{D}_{50}$ - flow rate" function for cyclone GK 2.69

\section{Cyclone GK 4.162 (Rascal)}

The Rascal cyclone (Mesa Laboratories, USA) is of similar construction to the GK 2.69 cyclone. It operates at a higher flow rate (8.5-9.5 L. $\left.\mathrm{min}^{-1}\right)$, when sampling the respirable aerosol fraction. The manufacturer does not indicate the flow rate for sampling the thoracic fraction. Thorpe (2011) measured the variation in $\mathrm{D}_{50}$ with respect to flow rate within the 7-10 L. $\mathrm{min}^{-1}$ range. At $7 \mathrm{~L} \cdot \mathrm{min}^{-1}$, the $\mathrm{D}_{50}$ was $4.9 \mu \mathrm{m}$. Using these data, Thorpe (2011) proposed a 
$D_{50}$-flow rate equation for the cyclone, specifically $D_{50}=10.826 \mathrm{e}^{-0.1138 \mathrm{Q}}\left(\mathrm{D}_{50}\right.$ is expressed in $\mu \mathrm{m}$ and $\mathrm{Q}$ is the flow rate expressed in $\left.\mathrm{L} \cdot \mathrm{min}^{-1}\right)$. It is obvious that the flow rate must be much lower than 7 L.min ${ }^{-1}$ in order to shift $D_{50}$ up to $10 \mu \mathrm{m}$, the aerodynamic diameter that corresponds to the cut point of the thoracic conventional curve. We experienced flow rates lower than $7 \mathrm{~L}$. $\mathrm{min}^{-1}$. Fig. 4a illustrates our results along with a new data fit. Fairly close agreement of these data between 10 and approximately 3.5 L. $\mathrm{min}^{-1}$ can be observed. The experimental $\mathrm{D}_{50}$ started to deviate from the fitted curve at lower flow rates. This was confirmed by new HSL data of Thorpe published in Lee et al. (2016).

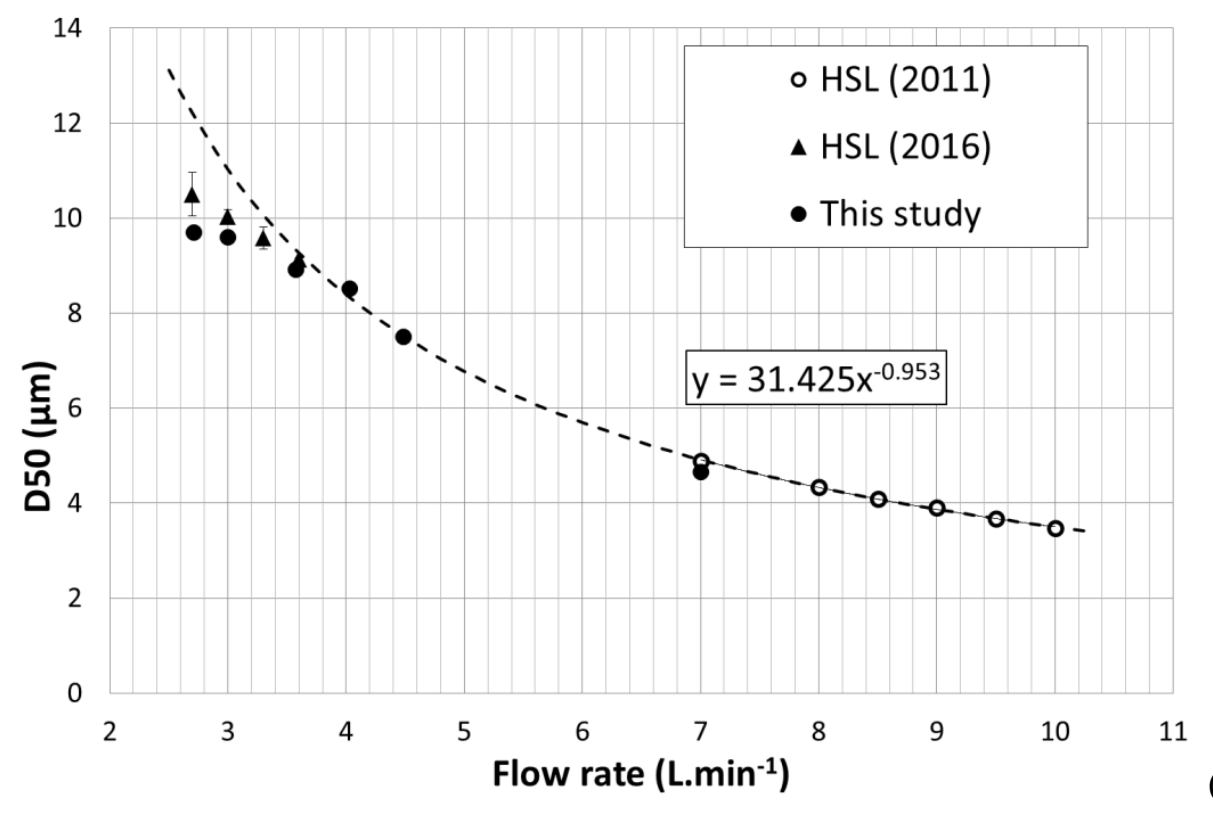

(a)

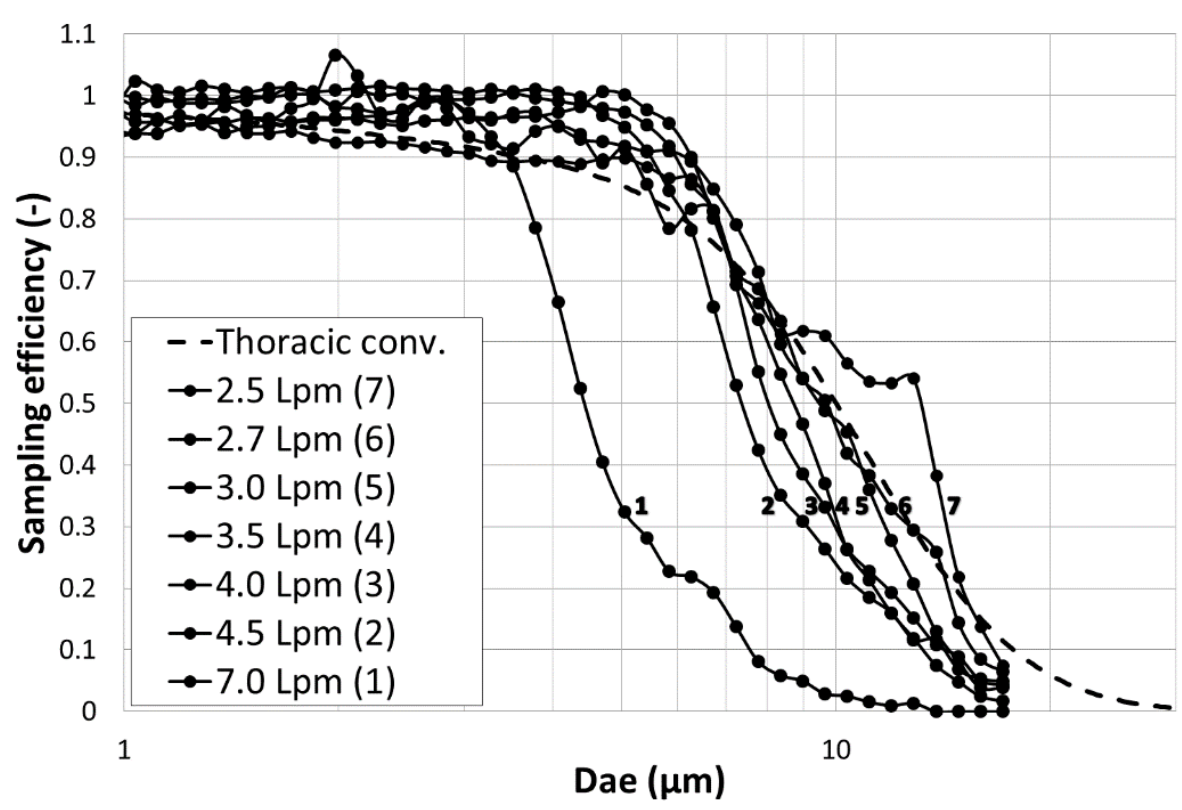

(b)

Fig. 4. "D $D_{50}$ vs. flow rate" function (a) and sampling efficiencies at different flow rates (b) of the Cyclone GK 4.162 (Rascal)

Fig. $4 \mathrm{~b}$ shows that the efficiency curves for flow rates below $3 \mathrm{~L} \cdot \mathrm{min}^{-1}$ start to be irregular and at $2.5 \mathrm{~L} \cdot \mathrm{min}^{-1}$, particle selection is entirely uncertain. In this condition, the flow velocity is probably too small to maintain the cyclone vortex. It follows that the $3 \mathrm{~L}^{-\mathrm{min}^{-1}}$ flow rate is the 
Rascal sampler's lowest limit of usage but it is otherwise very suitable for thoracic aerosol sampling.

Fig. 5a illustrates experimental efficiency points obtained in the horizontal low velocity wind tunnel with the sampler air flow rate of $3 \mathrm{~L} \cdot \mathrm{min}^{-1}$. These data are mean values of readings for three orientations (forward, left and right, 3 runs each) as used for the GK 2.69 cyclone.

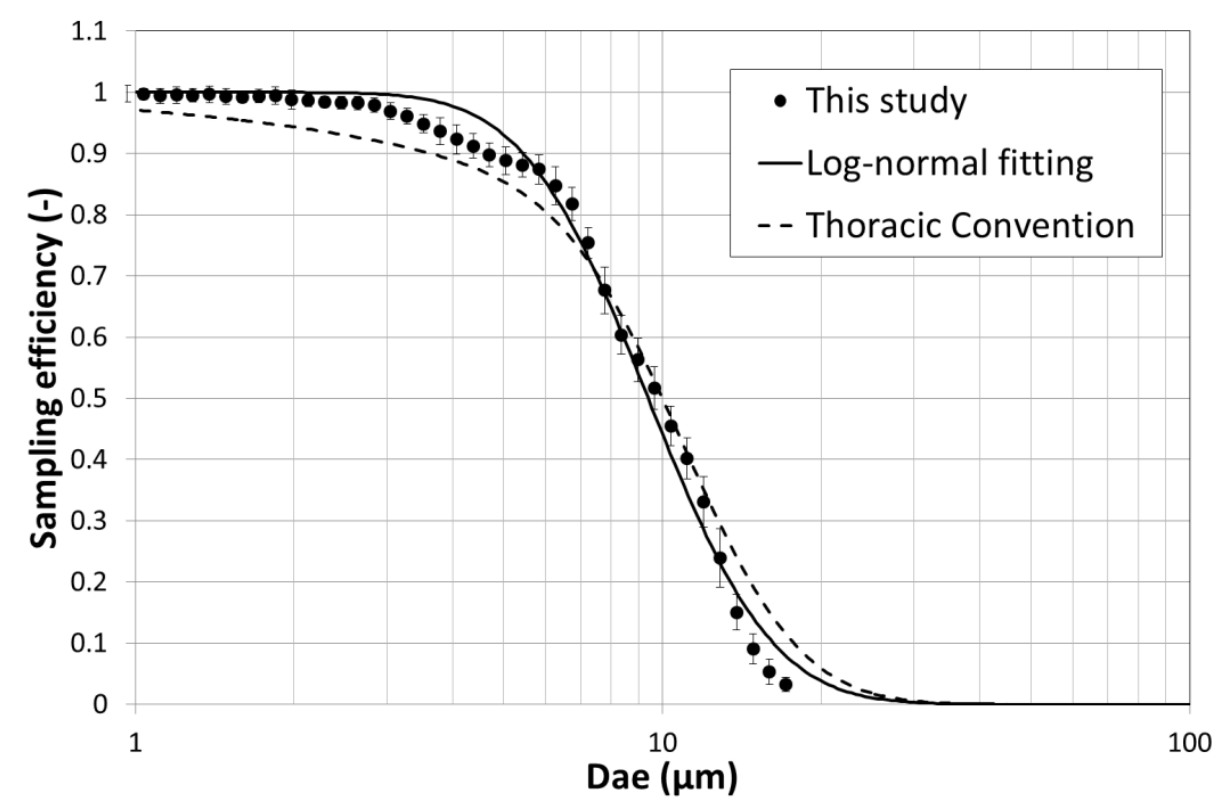

(a)

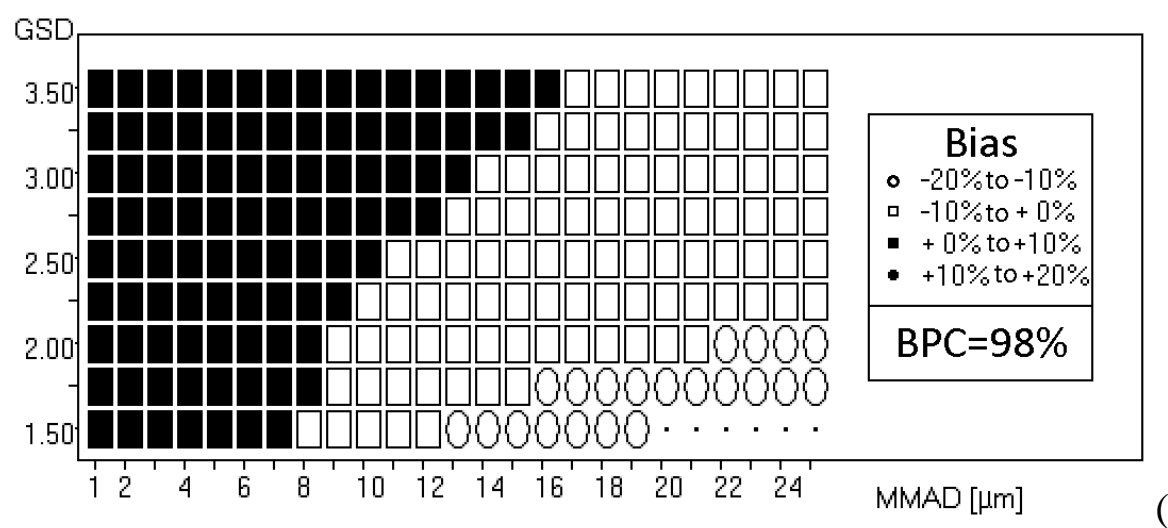

(b)

Fig. 5. Sampling efficiency (a) and bias map (b) of cyclone GK 4.162 operated at 3.0 L.min ${ }^{-1}$.

The solid line is the log normal fitting curve for the efficiency data. The bias map (Fig. 5b) was computed using the following optimized parameters:

$$
\begin{gathered}
\mathrm{D}_{50}=9.40 \mu \mathrm{m} \\
\mathrm{GSD}=1.53
\end{gathered}
$$

The bias map (Fig. 5b) shows that the GK 4.162 cyclone (Rascal-T) measures the particle mass concentration with an acceptable bias of $\pm 10 \%$ for $98 \%$ of aerosol distributions used for the BPC calculation.

In a recent study (Lee et al., 2016), Lee and Thorpe re-measured the sampling efficiency of this cyclone using two methods: polydisperse aerosol and APS for Thorpe and monodisperse aerosol and Scanning Electron Microscopy (SEM) for Lee. While the former 
established an optimal flow rate of between 2.7 and 3.3 L.min ${ }^{-1}$ for thoracic aerosol sampling, the latter reported the optimal flow rate to be $3.5 \mathrm{~L}_{\mathrm{min}}{ }^{-1}$. In conclusion, the authors stated, "Therefore, it is recommended that the GK 4.162 should be operated at a flow rate of 3.4 L. min $^{-1}$ pending information in other laboratories". In our study, the best BPC was found for a flow rate of 3.0 L. $\mathrm{min}^{-1}$, a value lying in the middle of Thorpe's interval.

\section{Cyclone IFA FSP10}

German occupational health and safety institute IFA (Institut für Arbeitsschutz) uses an FSP10 (Fein Staub Probe) high volume aerosol sampler for respirable particles in the workplace. This is a modified Cossey and Vaughan (1987) cyclone operated at $10{\mathrm{~L} . \mathrm{min}^{-1}}^{-1}$ designed by Riediger (1998-not published) at the BIA (Berufsgenossenschaftliches Institut für Arbeitssicherheit). Based on the original Cossey and Vaughan (1987) experimental ' $D_{50}$ vs. flow rate' function $\left(\mathrm{D}_{50}=68.7 \mathrm{Q}^{-1.15}\right.$, where $\mathrm{Q}$ is the flow rate in L. $\left.\mathrm{min}^{-1}\right)$ a new, stainless steel version of this cyclone was designed with intention to sample the thoracic fraction of the aerosol at a flow rate of 5.34 L.min ${ }^{-1}$ (Breuer et al., 2012).

We measured the efficiency of the German respirable cyclone FSP10 in late 1990s for former BIA institute at a flow rate of $10 \mathrm{~L} \cdot \mathrm{min}^{-1}$. Laboratory testing gave a steep penetration curve with $\mathrm{D}_{50}=4.37 \mu \mathrm{m}$, which agrees with the expected respirable fraction of the aerosol. The morphology of today's IFA cyclone is totally different; we therefore checked the respirable sampling efficiency of this cyclone prior to measuring its efficiency at $5.34 \mathrm{~L} . \mathrm{min}^{-1}$. The results obtained at $10{\mathrm{~L} . \mathrm{min}^{-1}}$ yield a cutoff diameter $\mathrm{D}_{50}$ close to $4 \mu \mathrm{m}$ (Fig. 6a), in accordance with our earlier measurement.

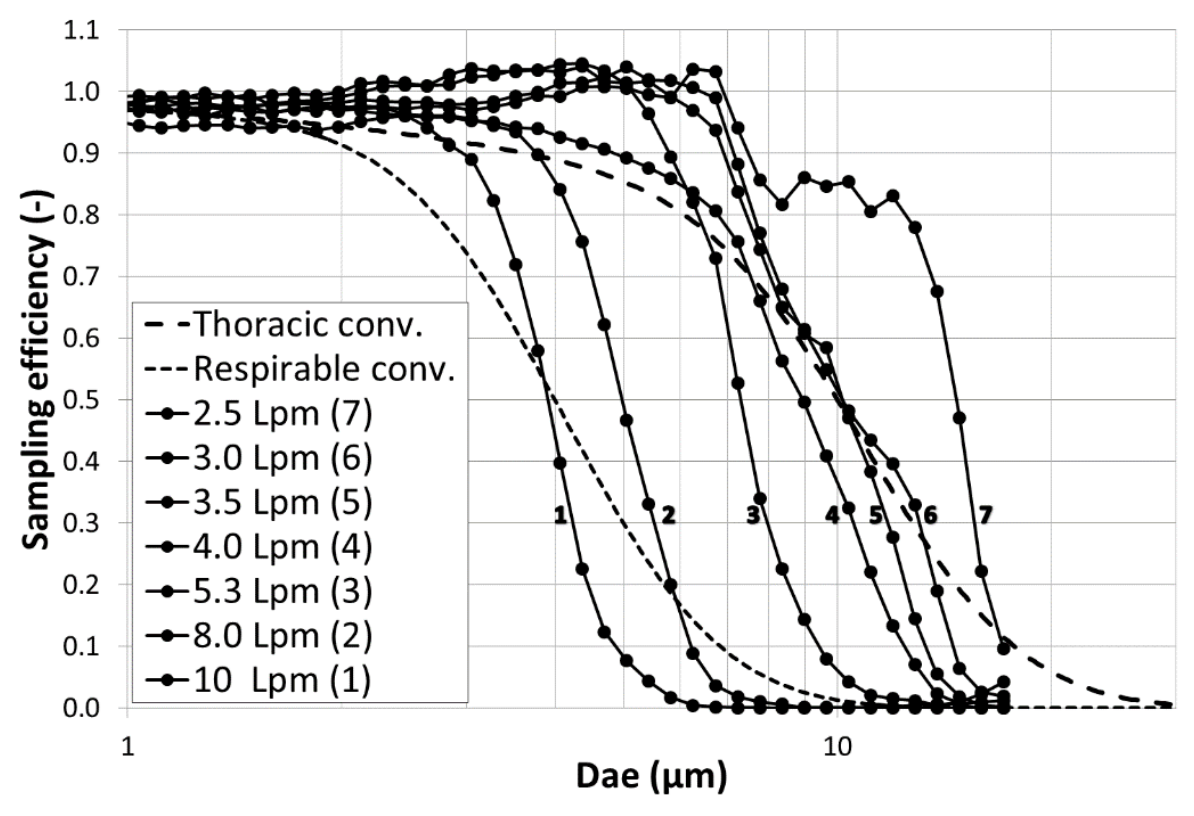

(a) 


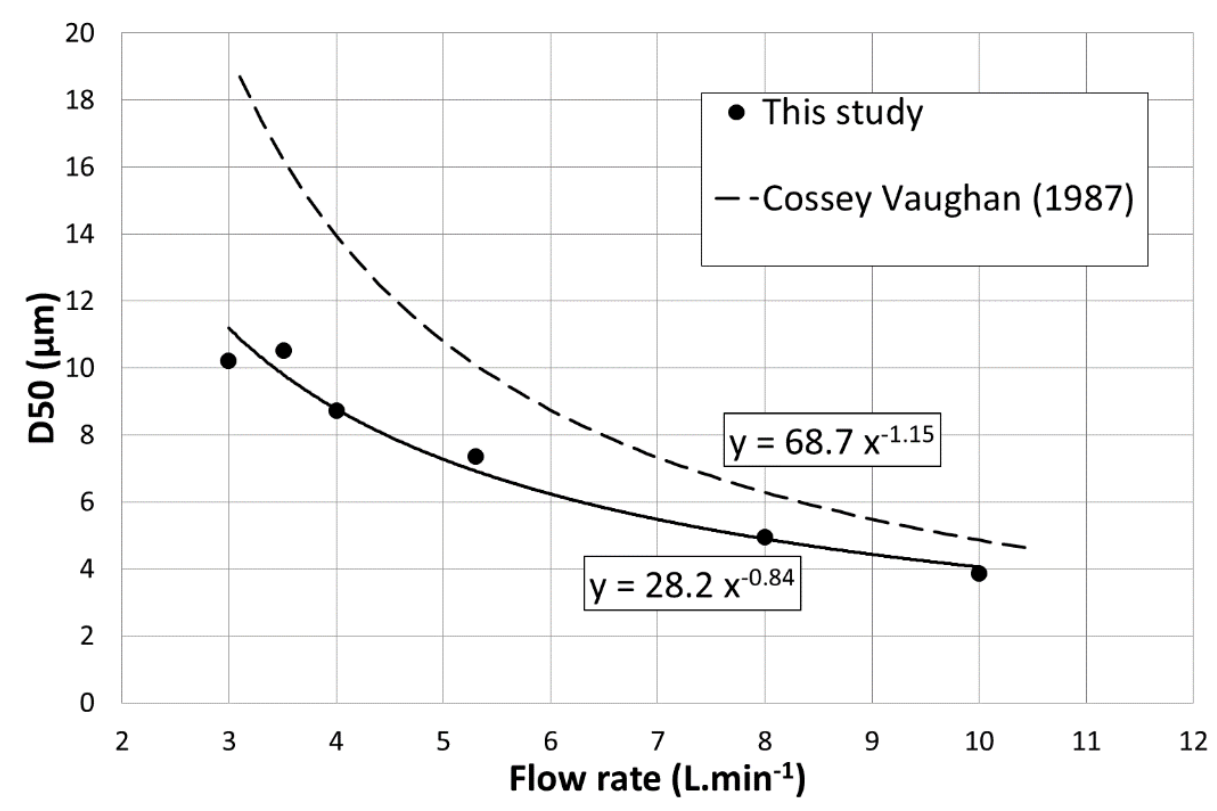

(b)

Fig. 6. Sampling efficiencies at different flow rates (a) and ' $D_{50}$ vs. flow rate' function (b) for the IFA FSP10 cyclone.

But, at a flow rate of $5.34 \mathrm{~L} \cdot \mathrm{min}^{-1}$ we found a cut point $\mathrm{D}_{50}=7.2 \mu \mathrm{m}$, which is far from the required $10 \mu \mathrm{m}$ for thoracic efficiency. The measured sampling efficiency of the cyclone for a series of flow rates ranging from 3 to $10 \mathrm{~L} \cdot \mathrm{min}^{-1}$ yields a $D_{50}=f(Q)$ function (Fig. 6b) different from that of Cossey and Vaughan (1987). The required $10 \mu \mathrm{m}$ cut point is approached between 3 and $3.5 \mathrm{~L} . \mathrm{min}^{-1}$. Precise determination of the optimum thoracic flow rate is rather difficult because the cyclone begins to operate irregularly in this range of flow rates and the vortex collapses at $2.5 \mathrm{~L} \mathrm{~min}^{-1}$ (Fig. 6a). Vaughan (1988) was the first to describe this phenomenon, stating, "There is a marked kink in the penetration curve for the lowest flow rate".

Fig. 7a illustrates the mean experimental data at $3.5 \mathrm{~L} \cdot \mathrm{min}^{-1}$ for nine efficiency measurements; three per forward, left and right position with respect to the horizontal low windspeed tunnel air flow. 


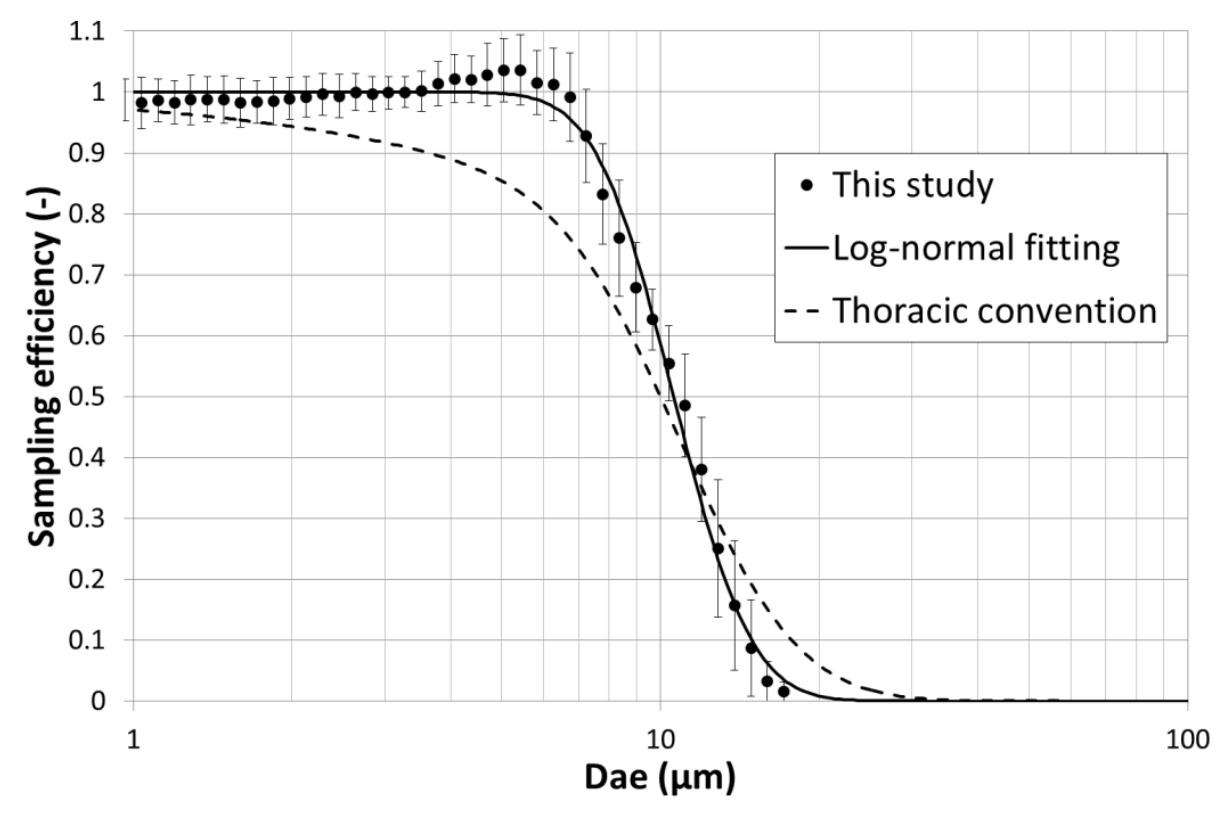

(a)

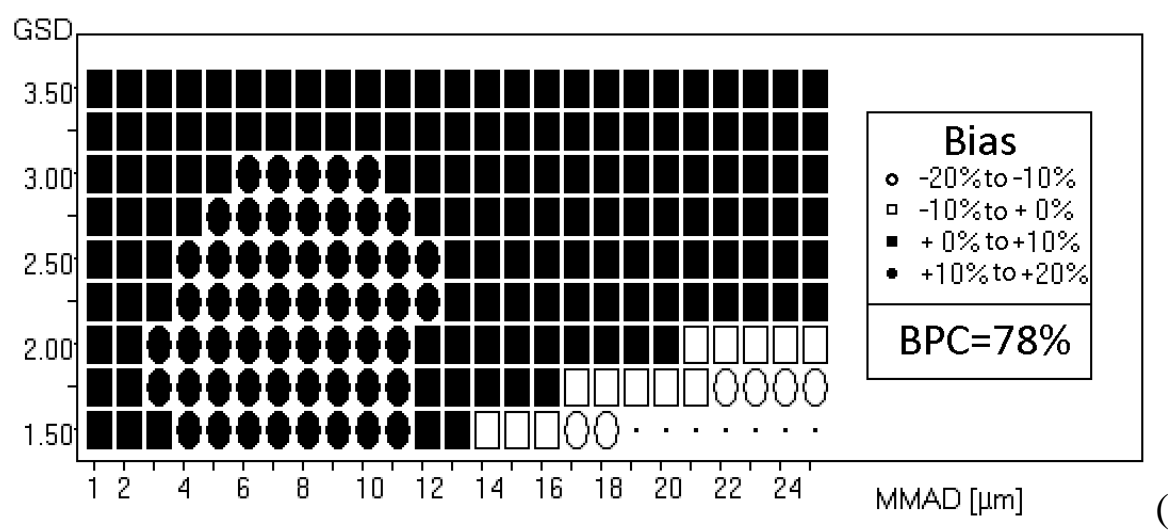

(b)

Fig. 7. Sampling efficiency (a) and bias map (b) of the IFA FSP10 cyclone at $3.5 \mathrm{~L}^{\mathrm{min}} \mathrm{m}^{-1}$

Fig. 7a shows that the cyclone has a steep separation curve. The best performance in thoracic sampling is met at a flow rate of $3.5 \mathrm{~L} . \mathrm{min}^{-1}$, where log normal fitting of the experimental data yields:

$$
\begin{gathered}
\mathrm{D}_{50}=10.59 \mu \mathrm{m} \\
\mathrm{GSD}=1.30
\end{gathered}
$$

Results of sampling efficiency (Fig. 7a) and performance of the IFA FSP10 cyclone (Fig. 7b) indicate that this is a good thoracic aerosol sampler at an optimum flow rate of 3.5 L.min ${ }^{-1}$. Lee et al. (2016) came close to the same result at 4 L. $\mathrm{min}^{-1}$ using a different method using six monodisperse aerosols.

Although the flow rate of $3.5 \mathrm{~L} \cdot \mathrm{min}^{-1}$ is more convenient for personal sampling than the former higher flow rate, the weight of the IFA FSP10 thoracic sampler makes it more suitable for static sampling.

\section{Parallel Particle Impactor - PPI-T}

The thoracic PPI-T (PPI, SKC, USA) was designed to sample the thoracic health-related aerosol fraction for assessment of worker personal exposure to airborne particles. It operates 
at a flow rate of $2 \mathrm{~L} \cdot \mathrm{min}^{-1}$. The thoracic aerosol fraction is selected by simultaneous implementation of four parallel impactor stages and a final collection filter. The thoracic sample consists of the particles collected on the final filter.

Fig. 8a illustrates the sampling efficiency for the PPI, measured in the horizontal low wind speed tunnel, along with data provided by Trakumas and Salter (2009). Both experimental data sets are very close and were fitted by above mentioned combined law.

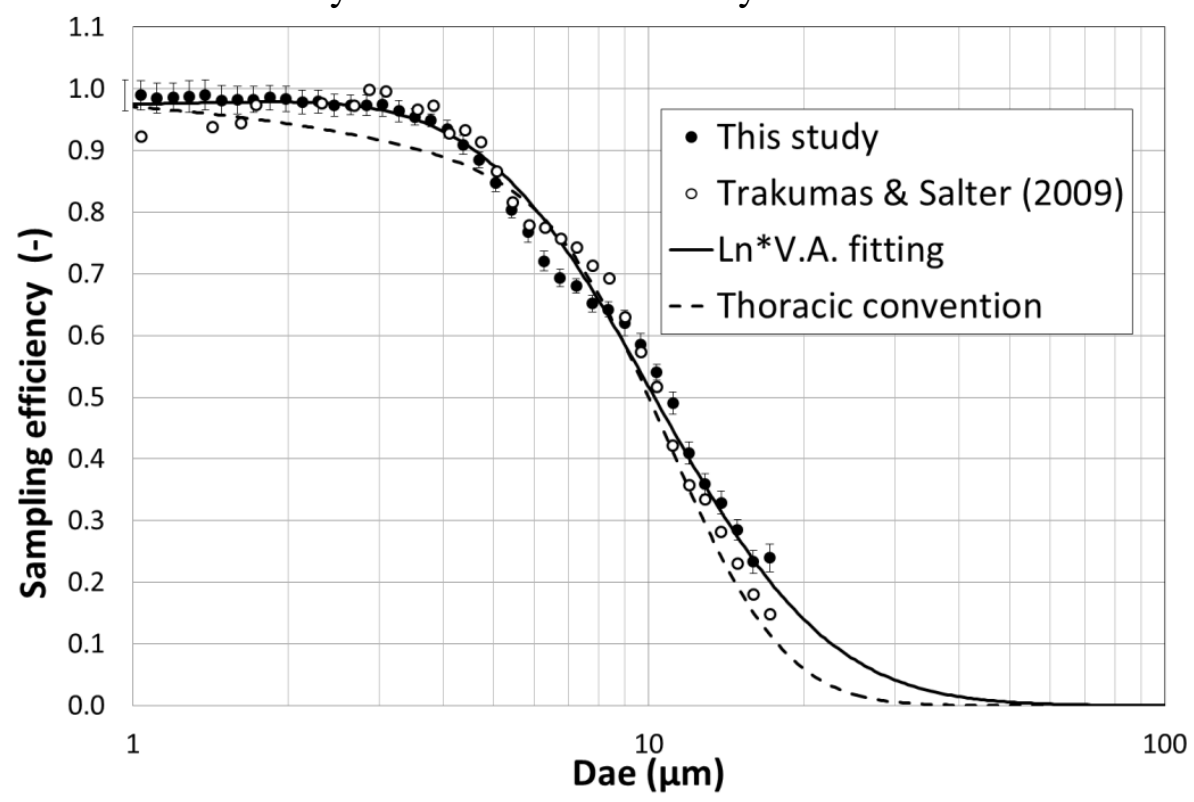

(a)

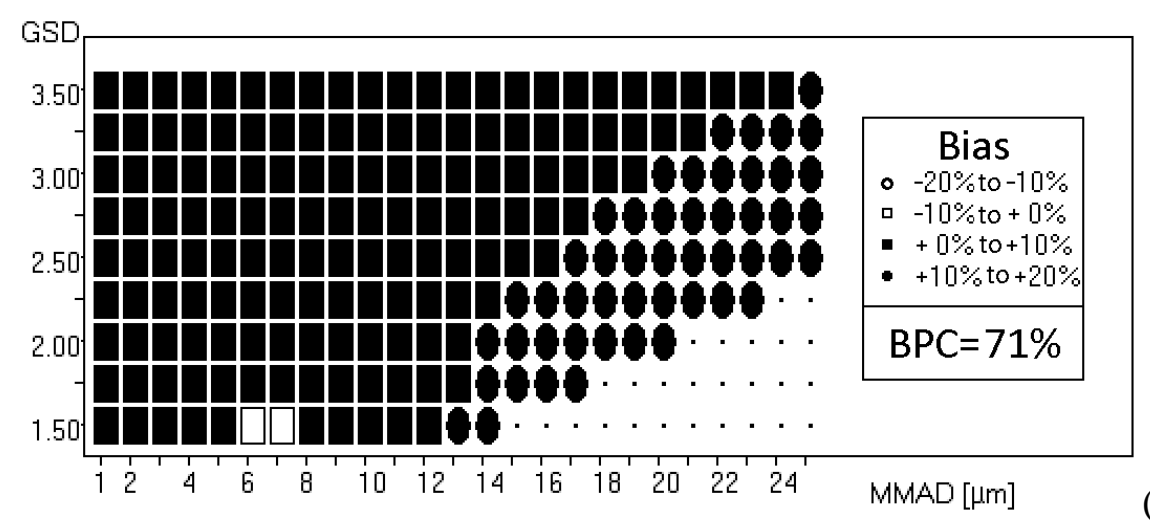

(b)

Fig. 8. Sampling efficiency (a) and bias map (b) of PPI thoracic aerosol sampler at 2.0 L.min ${ }^{-1}$

Adjusted parameters of the combined law applied to the PPI-T experimental data are:

$$
\begin{gathered}
\mathrm{D}_{50}=9.66 \mu \mathrm{m} \\
\mathrm{GSD}=1.89 \\
\mathrm{P}_{1}=0.484 \\
\mathrm{P}_{2}=0.015
\end{gathered}
$$

The modeled sampling efficiency curve (Fig. 8a) was compared to the conventional definition of thoracic penetration. Fig. 8b illustrates the bias map calculated for the thoracic PPI sampler. The PPI-T parallel impactor offers fair thoracic aerosol sampling performance for most particle size distributions present in the workplace (Fig. 8b). It will sample $71 \%$ of aerosols from the bias map with a positive bias smaler than $10 \%$. 


\section{CONCLUSION}

Five thoracic aerosol sampling devices were tested under laboratory conditions using a spherical polydisperse aerosol and the Aerodynamic Particle Sizer. The experimental method was checked by measuring the efficiency of known static thoracic sampler CATHIA-T. The sampling efficiency of the CATHIA-T turned out to be close to that found in previous studies. This proves the reliability of the experimental method implemented in this study. While it is not a personal sampler (due to size and high flow rate of $7 \mathrm{~L} \cdot \mathrm{min}^{-1}$ ), the CATHIA-T sampler has the advantage of collecting large quantity of particles for subsequent analysis.

Our results show that both BGI cyclones sample correctly the thoracic fraction of an ambient aerosol: the GK 2.69 at its nominal flow rate $1.6 \mathrm{~L} \cdot \mathrm{min}^{-1}$ and the GK 4.162 at a flow rate of $3.0 \mathrm{~L} . \mathrm{min}^{-1}$. Similar in performance to the GK 2.69 sampler, the GK 4.162 has the advantage of collecting almost twice the particulate matter thanks to its higher flow rate.

IFA cyclone FSP10 with its suggested $5.34 \mathrm{~L} \cdot \mathrm{min}^{-1}$ nominal flow rate did not assume conventional thoracic penetration. Our results show that cyclone samples the thoracic aerosol fairly well at the optimized flow rate of $3.5 \mathrm{~L} \cdot \mathrm{min}^{-1}$.

The IFA cyclone is much larger and heavier than the other cyclones, and is therefore less suited to personal exposure measurement.

The optimized low flow rates of both the IFA and GK 4.162 cyclones are close to the operating limit because the cyclonic vortex tends to collapse at approximately $2.5 \mathrm{~L} \cdot \mathrm{min}^{-1}$.

The Parallel Particle Impactor PPI-T was found to be a suitable thoracic aerosol sampler at its nominal flow rate of $2.0 \mathrm{~L} \cdot \mathrm{min}^{-1}$. It is small and lightweight, and is suitable for personal exposure measurement.

Aerosol sampling efficiency was measured using solid aerosol particles (glass beads) in this study. It was observed that sampling efficiency could vary depending on the particle phase. In theory, particle motion in air depends only on the aerodynamic size and shape of the particles. In practice, particles entering a sampler can come into contact with its walls and, in this case, solid particles will tend to rebound, while liquid particles will more easily adhere to the internal surfaces of the sampler. Sampler efficiency could therefore be slightly modified, in the case of liquid aerosol sampling in the workplace (e.g. sulfuric acid mist (EU 2009)). Prior to using aerosol samplers for liquid aerosol sampling, we recommend checking their sampler efficiency with at least one monodisperse liquid aerosol of approximately $10 \mu \mathrm{m}$ particle size, i.e. close to the expected $\mathrm{D}_{50}$ cut point.

A field study is planned to be carried out in different industrial situations to compare the behavior of thoracic samplers in workplace conditions. 


\section{REFERENCES}

ACGIH (1994-1995) Threshold limit values for chemical substances and physical agents and biological exposure indices. American Conference of Governmental Industrial Hygienists, Cincinnati, OH.

Baldwin PEJ, Maynard AD. (1998) A survey of wind speeds in indoor workplaces. Ann Occup Hyg; 42: $303-$ 313.

Breuer D, Heckmann P, Gusbeth K, Schwab G, Blaskowitz M, Moritz A. (2012) Sulfuric acid at workplaces applicability of the new Indicative Occupational Exposure Limit Value (IOELV) to thoracic particles. J Environ Monit; 14: 440-445.

CEN (1993) EN 481: Workplace atmospheres - Size fraction definitions for measurement of airborne particles. Comité Européen de Normalisation, Brussels.

CEN (2014) EN 13205: Workplace exposure - Assessment of sampler performance for measurement of airborne particle concentrations. Comité Européen de Normalisation, Brussels.

Cossey JR, Vaughan NP. (1987) A higher-flow rate cyclone for determination of respirable dust. Ann Occup Hyg; 31: 39-52.

Corn M. (1987) Methods to assess airborne concentrations of cotton dust. Am J Ind Med;12: 677-686.

Dement JM. (1990) Overview: Workshop on Fiber toxicology research needs. Environ Health Perspect; 88: 261268.

ISO (1995) IS 7708: Air quality - Particle size fraction definitions for health-related sampling. International Standards Organisation, Geneva.

EU (2009) Directive 161of European Commission from17 $7^{\text {th }}$ December 2009 establishing the third list of Occupational Exposure Limits. Journal Officiel de l'Union Européenne du 19.12.2009, L 338: 87-89.

Fabriès JF, Carton B. (1980) Realization of a dust tunnel - Response of some air sampling instruments used in industrial hygiene. Atmosph Pollution; 8: 279-283.

Fabriès JF, Carton B, Wrobel R. (1984) Equipment for the study of sampling instruments with real time measurement of the aerosol concentration. Staub - Reinhalt Luft; 44: 405-409.

Fabriès JF, Wrobel R, Görner P. (1988) Capteur individuel portatif pour recueillir une fraction déterminée des suspensions solides d'une atmosphère. French Patent $n^{\circ} 8815974,6^{\text {th }}$ December 1988.

Fabriès JF, Görner P, Kauffer E, Wrobel R, Vigneron JC. (1998) Personal thoracic CIP 10-T sampler and its static version CATHIA-T. Ann Occup Hyg; 42: 453-465.

Görner P, Fabriès JF. (1993) Aerosol sampler performance testing - Bias maps and classification index. In Proceedings of Symposium: Modern Principles of Workplace Air Monitoring, Geilo Norway; 15-18 Feb.: p.10.

Görner P, Fabriès JF. (1996) Industrial aerosol measurement according to the new sampling conventions. Occup Hyg; 3: 361-376.

Görner P, Simon X, Wrobel R, Kauffer E, Witschger O. (2010) Laboratory study of selected personal inhalable aerosol samplers. Ann Occup Hyg; 54: 165-187.

Görner P, Witschger O, Roger F, Wrobel R., Fabriès JF. (2008) Aerosol sampling by annular aspiration slots. J Environ Monit; 10: 1437-1447.

Görner P, Wrobel R., Fabriès JF. (2000) Experimental method to determine the efficiency of aerosol samplers using the Coulter Counter. J Aerosol Sci; 31, Suppl 1: S268-S269.

Görner P, Wrobel, R, Micka V, Skoda V, Denis J, Fabriès JF. (2001) Study of fifteen respirable aerosol samplers used in occupational hygiene. Ann Occup Hyg; 45: 43-54.

Grinshpun S, Willeke K, Kalator S. (1993) A general equation for aerosol aspiration by thin-walled sampling probes in calm and moving air. Atmos Environ; 27A: 1459-1470.

Guichard JC (1976) Aerosol generation using fluidised beds. In Liu BYH, editor. Fine Particles. New York: Academic Press. p. 173-193. ISBN 0-12-452950-X.

Hangal S, Willeke K. (1990) Overall efficiency of tubular inlets sampling at 0-90 degrees from horizontal aerosol flows. Atmos Environ; 24A: 2379-2386.

Jones AD, Aitken RJ, Fabriès JF, Kauffer E, Lidén G, Maynard A, Riediger G, Sahle W. (2005) Thoracic sizeselective sampling of fibres: Performance of four types of thoracic sampler in laboratory tests. Ann Occup Hyg; 49: 481-492.

Kauffer E, Vigneron JC, Fabrès JF, Billon-Galland MA, Brochard P. (1996) The use of a new static device based on the collection of the thoracic fraction for the assessment of the airborne concentration of asbestos fibres by transmission electron microscopy. Ann Occup Hyg; 40: 311-319.

Kenny LC, Gussman RA. (1997) Characterization and modeling of a family of cyclone aerosol preseparators. J Aerosol Sci; 28: 677-688.

Kenny LC. (2000) Aerosol Sampler Testing Exchange (ASTEX). J Aerosol Sci; 31, Suppl 1: S262-S263. 
Laurière M, Görner P, Bouchez-Mahiout I, Wrobel R. Breton C. Fabriès JF, Chouda D. (2008) Physical and biochemical properties of airborne flour particles involved in occupational asthma. Ann Occup Hyg; 52: 727-737.

Lee T, Kim SW, Chisholm WP, Slaven J, Harper M. (2010) Performance of high flow rate samplers for respirable particle collection. Ann Occup Hyg; 54: 697-709.

Lee T, Thorpe A, Cauda E, Harper M. (2016) Calibration of high flow rate thoracic-size selective samplers. J Occup Environ Hyg; 13: D93-D98

Lidén G, Kenny L.C. (1991) Comparison of measured respirable dust sampler penetration curves with sampling conventions. Ann Occup Hyg; 35: 485-504.

Lidén, G, Kenny, LC. (1992) The performance of respirable dust samplers: Sampler bias, precision and inaccuracy. Ann Occup Hyg; 36: 1-22.

Lidén G. (2000) Presentation of the results from round 1 of ASTEX. J Aerosol Sci; 31, Suppl 1: S270-S271.

Lippmann M, Gearhart JM, Schlesinger RB. (1987) Basis for a particle size-selective TLV for sulfuric acid aerosol. Appl Indust Hyg; 2: 188-199.

Lynch JR. (1970) Air sampling for cotton dust. In Trans. Nat. Conf. on Cotton Dust and Health. Univ.of North Carolina. Chapel Hill, NC. p. 33-43.

Maynard AD. (1999) Measurement of aerosol penetration through six personal thoracic samplers under calm air conditions. J Aerosol Sci; 30: 1227-1242.

Maynard AD. (2002) Thoracic size-selection of fibres: Dependence of penetration on fibre length for five thoracic sampler types. Ann Occup Hyg; 46: 511-522.

Soderholm SC. (1989) Proposed international conventions for particle size-selective sampling. Ann Occup Hyg; 33: 301-320.

Soskolne CL, Zeighami EA, Hanis NM, Kupper LL, Hermann N, Amsel J et al. (1984) Laryngeal cancer and occupational exposure to sulfuric acid. Am J Epidem; 120: 358-369.

Soskolne CL, Jhangri GS, Scott HM, Brenner DR, Siematycki J, Lakhani R, Gérin M et al. (2011) A populationbased case-control study of occupational exposure to acids and the risk of lung cancer: Evidence of specificity of association. Int J Occup Environ Health; 17: 1-8.

Stacey P, Lee T, Thorpe A, Roberts P, Frost G, Harper M. (2014) Collection efficiencies of high flow rate personal respirable samplers when measuring Arizona road dust and analysis of quartz by X-ray diffraction. Ann Occup Hyg; 58: 512-523.

Thorpe A. (2011) Evaluation of the penetration characteristics of a high flow rate personal cyclone sampler for NIOSH. Health \& Safety Lab. report EMC/2011/03, Harpur Hill, Buxton, UK.

Trakumas S, Salter E. (2009) Parallel particle impactor - novel size-selective particle sampler for accurate fractioning of inhalable particles. J Physics: Conf Series 151, doi: 10.1088/1742-6596/151/1/012060.

Vaughan NP. (1988) Construction and testing of an axial flow cyclone preseparator. J Aerosol Sci; 19: 295-305.

Vincent JH, Armbruster L. (1981) On the quantitative definition of the inhalability of airborne dust. Ann Occup Hyg; 24: 245-248. 